\title{
An Analysis of Influencing Factors of Innovative Education and Development Proposals
}

\author{
Zhaoji Yu \\ Shenyang University of Technology \\ Shenyang, China \\ shengchanjihua999@vip.sina.com
}

\author{
Songtao Zhou \\ Shenyang University of Technology \\ Shenyang, China \\ zhou928590574@163.com
}

\author{
Yingmo Li \\ Shenyang University of Technology \\ Shenyang, China \\ li_ying_mo@sina.com
}

\begin{abstract}
To research and analyze the acting factor of the Innovation Education is the basis of making clear of the causal relationship of the parts of the process of innovation education. This article is aiming to analyze the internal and external system of the educational institutions and the causal relationships between factors in order to catch the critical factors to render some perfect and reasonable development proposals. What's more, we also analyze the effect relationship of each factor for the cause of seizing the key influence factors, which $I$ think is important to solve the problems of the process and the level of innovation education.
\end{abstract}

Keywords-innocative education; innovative practice; influencing factors; educational assessment

\section{INTRODUCTION}

Innovative education is the education that is used to foster innovation ability and creative spirit as its basic value orientation [1]. Innovative education mainly includes the following four aspects: First, wake up students' critical awareness and encourage students to find the courage to question; Second, it encourage students to adhere to innovation activities, innovation internalized into the living habits; third, students 'creative thinking is exercised in education and teaching process; Fourth, through education, training and ability to develop students' creative practice .

The State Council promulgated the "State long-term scientific and technological development program", that "the construction of an innovative country as a major strategic choice for the future", setting off a national educational research scholars on innovation boom in 2006. Ma Jingzhong (2013) summarized the development of education and developed innovative features, in-depth analyze the development of innovative education problems and its constraints, analysts pointed out that the influence of traditional culture, education itself factors, educational evaluation methods and evaluation system defects and their quality educators are main factors that restrict our innovative education, and they explored the ways to accelerate the establishment of operational mechanisms for innovative education and countermeasures for these four aspects [2].
However, their research study on constraints is not deep enough, and lack of a systematic analysis of the relationship and mutual influence. through the analysis of educational institutions, business organizations, government departments, experts and scholars and professionals interviews, questionnaires in Zhejiang, Zhou Yaolie and Wang Qian (2010) further determine the factors influencing of personnel training innovation system based on the government $(\mathrm{G})$, educational institutions(E) and business organizations $(\mathrm{O})$, and through regression analysis to establish a dominant factor in the regression model, a clear interaction between each of the major variables affecting the relationship [3]. According to the system theory, Hu Rui, etc. (2011) points out that the impact factors of innovative education should include three levels: from the internal student education systems, the impact factor is the training mode; from the point of school education subsystem, its impact factor is the management model; from the view of social subsystems, the impact factor is the culture environment [4]. Zhang Yuchen (2013) and others take think the innovative education rationally from the political, economic and cultural dimensions of college students [5]. Zhang Shuguo (2012) pointed out that education must be innovative teaching ideas and teaching methods of innovation, reform the traditional teaching model, and build a new innovation-oriented training system in order to achieve the objective of fostering innovative talents [6]. Zhou Qingming and Liu Jing (2012) through the analysis of the relationship between the innovative education and employment pointed out the impact of the awareness of innovative education to employment, employment planning, competitiveness and employment [7].

From review of literature found that although there are many domestic scholars study the innovative education, but the research focused largely on the definition of innovative concepts, innovative education problems and innovative educational approaches and modes of implementation, and lack of its cause of the problem analysis, especially lack of the analysis of innovative education influencing factors. Our article is based on these. The paper analyses the factors affecting the mechanism and role of the principle of the system 
dynamics causal analysis, and strives to find ways to improve the level of innovation and the key role of education points.

\section{THE FRAMEWORK OF INNOVATIVE EDUCATIONAL FACTORS}

Educational institutions are the carrier of innovative education, innovation and education directly affects the level of development. For example, firstly according to market requirements and economic development, colleges and universities develop innovative education goals, according to the innovative educational goals down to every level, combining all aspects of school conditions to make a suitable school develop innovative educational programs, and then follow the innovative education program and training, taking the innovative education teaching quality assessment after the

and education, such as training and quality assessment, daring and innovative cultural spirit of face to failure can stimulate students' initiative better, improve the subjective quality of innovation education, enhance the innovative capability increased. Market environment impact education on innovation enterprises, mainly refers to the impact of the employer, the employer is the subject who request innovative education, the development goals of innovation educational are training, through the analysis of the evaluation results to set innovative educational goals for the next year, and complete the development of innovative education college's internal system cycle. In addition, innovative education also strongly influenced by the external environment, which includs the policy environment, market environment and the cultural environment. All of the educational institutions, behavior and activities will be subject to legal constraints and policy norms, government policy play an irreplaceable role in innovation education and training program development, supervision and training process and develop quality evaluation and certification etc., therefore government policy must be taken seriously in the study of innovative education factors.

Cultural environment is the main factor that affect two aspects of the process of innovation

setting around the market requirements, innovative education quality are evaluated also by employer's assessment, especially enterprise as an innovative educational services mainly their different needs to innovative talents make out a higher requirement for innovative education. Through the above analysis to build innovative education influencing factors analysis framework shown in Figure I .

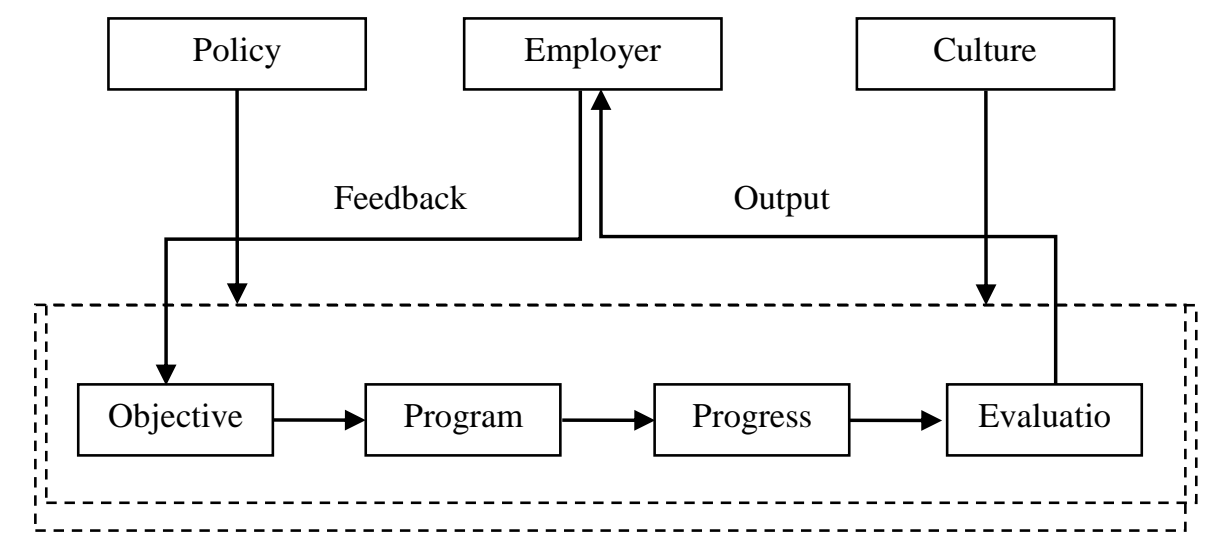

FIGURE I FACTORS ANALYSIS FRAMEWORK OF INNOVATIVE EDUCATION INFLUENCING

\section{THE PROBLEMS AND INFLUENCE FACTORS OF INNOVATIVE EDUCATION}

(1) The factors of internal educational institutions

Designing innovative educational objectives is a starting point for the implementation of innovative education, the understanding of the spirit of innovation education goals for practicality, flexibility and critical direct impact on the development of innovative educational programs. Educational programs reflect the acceptance of innovation and implementation efforts. In actual teaching, programs that can be implemented will be a lot of innovative ideas from outside, choose the right from the innovative educational programs, to determine the most satisfactory one. The main factors impact decision-making about innovative education programs and its target are innovative cultural environment and educational institution management system from government department.
Innovative educational program development determines the management of educational institutions, teaching programs, teaching materials selection and curriculum design. This four-part educational process is carried out the major part to achieve innovative education. Open management model to create a fair and active academic atmosphere that conducive to stimulate students' creative thinking, the acceptance and recognition of failure in management mode can greatly promote students dare to innovate practice and encourage students to keep spirit of adventure and critical attitude to guide students continue to innovate. Innovative education teaching methods affect the key active teaching in the classroom, students can engage in a vigorous discussion and dialectic, fully show their individualities, break the traditional teaching methods, the new method allow students to attempt to diverge type of thinking, by which teachers and students can discuss progress together in class. The choice of materials is an auxiliary tool for innovative education, scientific teaching material system can give students a new way of thinking and 
open form of operations, to stimulate student interest in learning and learning initiative, to promote in-depth study the relevant aspects of the course and discussion to help students achieve a breakthrough innovation. Curriculum design is carried out in the program teaching objectives, adding some courses apart from traditional practice teaching curriculum such as computer experiment, ERP and enterprise simulation laboratory simulations etc., some colleges and universities also set corporate internships and field research as compulsory cause to improve the abilities of students, more importantly, while studying in practice students' divergent thinking and exploration of the unknown is arouse. Because educational background, life experience, innovative ideas and personality are different, each teacher's teaching programs are not the same, the construction of teachers is particularly important.

\section{(2) External factors of educational institutions}

Employers mainly affect three aspects. Firstly, enterprise with educational institutions jointly established innovative practice platform for the students to provide opportunities to practice; secondly, enterprise provide funds for investment in education, R\&D or personnel training; thirdly, enterprise take part in innovative education quality assessment, make appraisal from the creative talent in the enterprise application, reflect personnel problems in the application and effectiveness. On the one hand, a good external help cultivate culture of adventure spirit and innovative ideas within the university, changing the concept of teachers and students about educational philosophy and school characteristics, to create a unique and innovative college cultural environment. On the other hand, the external culture can affect the development of the corporate culture, senior management's views are changed, pay more attention to the cultivation of innovative talents and innovation capacity, promote innovation platform units to build, funds for educational institutions is increasing and innovative education quality assessment is timely fed back. Government impact on innovation education by educational funding, education system management and quality certification system. open educational institutions management system is able to relax the policy, activate power of educational institutions, more flexible teaching mode, teaching goal-setting, teaching program design, teaching practice, teaching assessment and other aspects of the development of education regulations have played a huge role; funding of educational institutions for innovative education provide strong logistical support; quality certification system is able to assess the quality of education in innovation part of the contents to be sure to protect the results of innovative education and legal effect.

(3) The impact analysis of relationship between internal and external of educational institutions

The quality evaluation process of innovative education not only to take into account students' professional knowledge, but also consider their ability to innovate. Apart from curriculum design, materials selection and teaching methods, innovation capability is more affected by the innovative practice. Innovative practices is an important part of innovation ability in education institutions. Educational institutions and employers provide students with opportunities to practice innovation, carry out a variety of innovative practices activity by the creation of innovative educational practice platform, their innovation labs and interdisciplinary training platform. As part of the university culture in multidisciplinary platform for the exchange of learning, the formation of mathematical modeling teams participate in the competition in innovation lab and develope intelligent robots and conduct business operations simulation. School-enterprise cooperation platform for innovative educational practice allows students early to get up with business operations, know the requirement of knowledge and skills of the business in practice, improve awareness courses to enhance the knowledge and skills of applications. Through courses, design, internship experience, innovation and competition results, teachers or employers on student performance make out the innovation capability assessment, combined with professional knowledge examination, final assess innovative education quality. Meanwhile, the quality assessment of innovative educational institutions is part of government departments performs quality assurance system, which requires policy of quality assurance system can adapt to innovative educational assessment, it's conducive to implement and enhanc control policy.

In addition, educational institutions innovative education financing is primarily used for faculty and infrastructure construction. Infrastructure is the premise and guarantee facilities of implementing innovative education, educational institutions, innovation and laboratory construction, multi-disciplinary and building cross-training platform, and printed and distribut promotional material of culture innovation need a lot of money for security. The investment of related simulations software, multimedia and the internet has also played a huge role in promoting and improving teaching methods. In addition to these hardware investments, the construction of teachers is also inseparable from innovative education funds, these can provide innovative learning and training opportunities to improve teachers' knowledge and understanding of innovation, assist teachers to reform the education system and teaching methods. After creative talents into the enterprises, compared with the employer's innovation requirements, innovative talents points added to innovative education evaluation system and was assessed by the employer's office and assessment, their advantages and disadvantages were found, and then back to the educational institutions and adjust innovate educational goals, redevelop, implement and evaluate teaching programs, to achieve a virtuous cycle of innovation education.

Using the system dynamics software VENSIM, innovative education affect elements of the relationship represented in Figure II . 


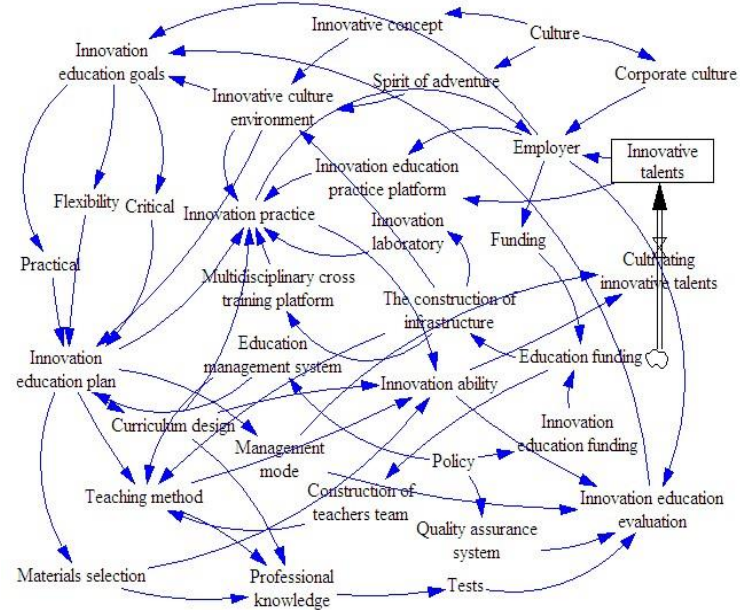

FIGURE II INNOVATIVE EDUCATION AFFECT ELEMENTS OF THE RELATIONSHIP

\section{DEVELOPMENT PROPOSALS OF INNOVATIVE EDUCATION}

Through the above analysis of key factors of innovative Education, relationship between the factors of influence for innovative educational practices is clear and identify the focal point, take a clear direction of innovative educational practices. Carry out innovative education, we need to fundamentally change the ideas, and create a vibrant culture environment, and enhance students' sense of innovation, improve innovation management system, construct a platform for innovative practices to improve the teaching programs, and build an innovative division team, specific measures are as follows.

\section{(1) Changing concepts of education}

In the process of teaching, enhancing students' awareness of innovation and changing the traditional educational values are assurances of innovative education to be implemented and major bottleneck. Affected by the traditional ideas, contemporary education strongly dependence on the authority and can't get rid of the shackles of traditional thinking, so innovative education is difficult to be carried out, resulting in most of the innovative education as a mere formality and the lack of effective progress. To come ture educational innovation, the concept shackles of inherent ideology must be broken, train students' dare to challenge authority and question existing answers. Strengthen the students' innovative spirit, develop their courage to face the failure of courage to recognize that innovation is not easy and require long-term accumulation and learning, provided the impetus for students' professional knowledge accumulation in the side. In addition, establish the overall development innovative educational concepts of students, practically train innovative talents. Therefore, changing concepts of education and strengthen their sense of innovation is source power to achieve innovative education.

\section{(2) Creating a free and active academic environment}

Lively campus atmosphere conducive to the cultivation of innovative talents, innovative culture can guide students to form innovative thinking by creating a favorable environment for promoting freedom, democracy, scientific learning atmosphere. Educational institutions completely emancipate students' mind by organizing a rich cultural program and increasing debate activities, the formation of interdisciplinary communication platform can promote the students continue, mutual integration of various disciplines to form a complete scientific system. In addition, encourage students to be actively take part in research activities, theoretical knowledge associated with the actual situation, found the problem and solves problems in the survey, enhance their understanding, establishing a scientific skepticism, the courage to challenge, dares to innovate.

\section{(3) Optimizing curriculum system}

Innovation comes from innovative thinking, creative thinking must be built on a solid fundamental and integrited professional knowledge. Optimize the curriculum system is not only to reoptimize the integration of traditional curriculum, the creation of the diversity of elective courses and to enhance the proportion of innovative curriculum, but also to focus on practical courses understanding, combined with practical application and theoretical knowledge, innovative laboratories, schools and enterprises practical cooperation platform for innovation and the effective application of interdisciplinary platform can enhance students' ability to apply theory in practice, thinking, analyze problems and guided by teachers engaged in a heated discussion, and the results were effectively organized and backuped. Guide students to spontaneously learn and think aboout the relevant content, and the collation of relevant learning content as the basis part of the final course score. while optimizing curriculum, school also fully optimized academic, student and graduate management mechanism, implement recognition among interdisciplinary elective credits and promote student disciplines to intersect, this is conducive to the formation of innovation and stimulate students' creative inspiration.

(4) Reforming teaching methods

At present, classroom teaching is still the main form of our country. It is a direct platform to impart knowledge, optimization and improvement of innovate teaching methods is the first step to develop students ability. With the form of multimedia teaching and discussion groups open teaching, carrying out heuristic, problem-based, inquiry-based discussion and other forms of teaching methods, to cultivate students' ability of think independently. In discussing, multi-point is collide, innovation inspiration inspires students to expand students' divergent thinking and critical thinking, improve their ability to innovate.

\section{(5)Strengthening practical teaching innovation}

Students' ability to apply the knowledge and practice of analytical ability can be tested by practical teaching, and detect the lack of teaching, to correct teaching programs' errors. Therefore, educational institutions should vigorously strengthen buliding of the practice platform. Various forms of practical innovation and regularly organize students into cooperative enterprise internship visits, expand extracurricular activities, to carry out industrial upgrading inspection, production practices and other operational training activities organized research project activities to broaden channels of practice teaching, enhance students' learning enthusiasm and 
innovation initiative. In the process of teaching, strengthens the supervision and management of teaching practice, and enhances the practice of teaching controllability and maneuverability of a comprehensive audit assessment mechanism, useing a comprehensive multi-index empowerment heavy scoring method. Students participate in teaching, in the process of founding problem and solving practical problems by knowledge, enhance their ability to innovate.

(6) Building innovative educational practice platform

As the limited resources of educational institutions, it cannot meet the students' requirements of practice teaching and participate in flexible and innovative activities. Therefore, should make full use of social resources, schools and enterprises to achieve win-win platform for building innovative educational practices. Through use of practice platform and related innovation laboratory, the school's research were turned into the social productive forces, to make up the lack of funds for school while train students' capabilities of innovation. Students can also communicate with employees and learning in innovative practice platform, help students broaden their horizons and raise their awareness, companies are able to found students who meet the business requirements in practice. In addition, through an open teaching laboratories, research and innovation activities build a platform to stimulate students' interest in scientific research, to develop their ability to innovate.

\section{ACKNOWLEDGMENTS}

This paper was supported by The national soft science support program(2012GXS4D078); Program for Liaoning Excellent Talents in University (WR2012003);2012 Liaoning Province Education Science "Twelve Five" project (JG12DB366).

\section{REFERENCES}

[1] Su Wangchu, Diao Hailin, Peng Qiong. Construction and practice of practical teaching system for innovative education[J]. Higher Education Forum ,2012,7:37 -39.

[2] Ma Jingzhong. Drawing on international experience in developing innovative educational approaches in Chinese universities and the countermeasures [J]. Education Forum ,2013,05:1 -3.

[3] Zhou Yaolie, Wang Qian. An empirical study on innovative education factors based on GEO [J]. Technology Progress and Policy, 2010,27 (10 ) :133- 136.

[4] Hu Rui, Li Zhongyun, Chen Xin. An analysis of graduate-education influential factors from system-theory perspective [J]. Educational theory and practice, 2011,31(1):3-5.

[5] Zhang Yuchen, Niu Yongjun, Tang Shenghua. Innovative education on college students' rational thinking [J] .2013,02:275.

[6] Zhang Shuguo. Higher Education research and practice of college Students' innovative exploration [J]. Hudson Normal University (Humanities and Social Sciences), 2012,1:168 -170.

[7] Zhou Qingming, Liu Jing. The research on local university innovative education to the effect of the employment of undergraduates take Hunan Agriculture University as the example [D]. Wuhan: Hunan Agricultural University, 2012. 